\title{
Commentary on the impacts of postoperative complications on survival after lung cancer surgery
}

\author{
Xinghua Cheng, MD, PhD, and Haiquan Chen, $\mathrm{MD}$
}

\author{
From the Department of Thoracic Surgery, Fudan University Shanghai Cancer Center, Shanghai, China. \\ Disclosures: Authors have nothing to disclose with regard to commercial support. \\ Received for publication Oct 20, 2017; accepted for publication Oct 26, 2017; available ahead of print Nov 29, \\ 2017. \\ Address for reprints: Haiquan Chen, MD, Department of Thoracic Surgery, Fudan University Shanghai Cancer \\ Center, 270 Dong An Rd, Shanghai 200032, China (E-mail: hqchen1@yahoo.com). \\ J Thorac Cardiovasc Surg 2018;155:1265-6 \\ 0022-5223/\$36.00 \\ Copyright (C) 2017 by The American Association for Thoracic Surgery \\ https://doi.org/10.1016/j.jtcvs.2017.10.122
}

Postoperative complications are common in thoracic surgery and are usually used as measurements of surgical quality. Previously, Rueth and colleagues ${ }^{1}$ reported that surgical complications in general may have adverse effects on the survival of patients after lung cancer surgery. The impacts of individual complications on survival, however, were not discussed. To address this question, Fernandez and colleagues $^{2}$ extracted 19 complications from the Society of Thoracic Surgeons General Thoracic Surgery Database and linked each patient's data with the survival record in the Medicare database. The associations between each individual recorded complication and the mortality were investigated at different postoperative phases (within 90 days, 318 months, and beyond 18 months). Eventually, a total of 29,899 patients were matched for analysis. The median age was 73 years (range, 69-78 years), and most of the patients $(86.9 \%)$ had an American Society of Anesthesiologists classification of III or greater.

There are several significant findings in this study. First, according to the analysis, some of the complications, such as initial ventilation for longer than 48 hours and unexpected return to the operating room, were not associated with increased risk of death at any phase after surgery. This is an important message to surgeons, because one should not be hesitant to perform early aggressive intervention, even in this relatively weak population. Other complications, such as pneumonia, myocardial infarction, and central neurologic events, may have been associated with increased mortality, but the effects dissipated after 3 months. It is unlikely that these complications would have significant impact on the oncologic effectiveness of the surgery. In contrast, patients who had blood transfusion or sepsis had diminished survival even after 18 months; whether this was because of tumor recurrence was not reported. These findings further support the importance of rescuing patients from complications immediately after the surgery. They also provide useful information to physicians during the follow-up of patients

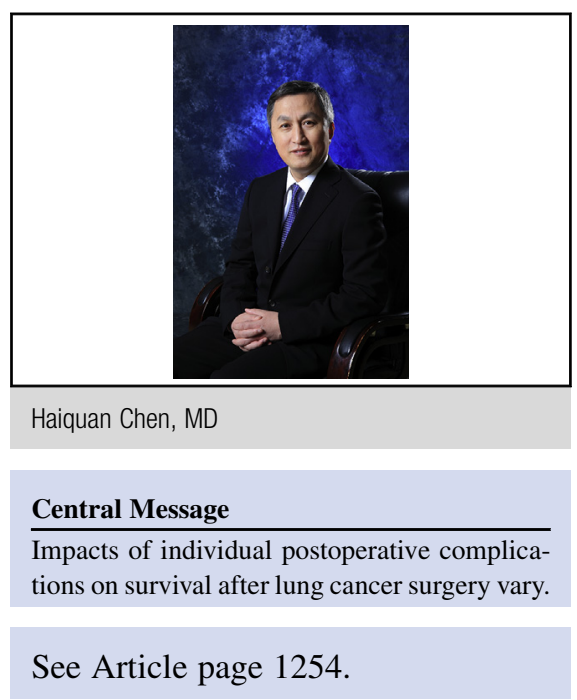

who have survived initial complications. Moreover, as Fernandez and colleagues ${ }^{2}$ suggested, future quality control systems and risk evaluation models should also consider varied weights of different complications according to their impacts on survival instead of arbitrarily assigning even weights.

Because this was a retrospective study and some details were missing from the public database, some potential confounding factors need to be considered when interpreting the results of this study. For example, instead of having a direct impact on survival, is it possible that the complications were reflections of poorer preoperative conditions of the patients, so these patients were generally less tolerant of the surgical insult? In addition, $17.4 \%$ of the patients had wedge resections, which are known to be associated with lower morbidity but a worse long-term survival. ${ }^{3} \mathrm{Un}$ balanced wedge resection rates thus may confound survival outcomes of patients, with or without postoperative complications. In addition, because the causes of death were missing, whether the complications may have increased cancer-related death risk is still unknown. Nevertheless, this is a good start for improved patient management and more accurate quality control in lung cancer surgery. Further investigations and validations of the findings are worthwhile.

\section{References}

1. Rueth NM, Parsons HM, Habermann EB, Groth SS, Virnig BA, Tuttle TM, et al The long-term impact of surgical complications after resection of stage I nonsmall cell lung cancer: a population-based survival analysis. Ann Surg. 2011;254: 368-74. 
2. Fernandez FG, Kosinski AS, Furnary AP, Onaitis M, Kim S, Habib RH, et al. Differential impact of operative complications on survival following surgery for primary lung cancer. J Thorac Cardiovasc Surg. 2018;155: 1254-64.
3. Dai C, Shen J, Ren Y, Zhong S, Zheng H, He J, et al. Choice of surgical procedure for patients with non-small-cell lung cancer $\leq 1 \mathrm{~cm}$ or $>1$ to $2 \mathrm{~cm}$ among lobectomy, segmentectomy, and wedge resection: a population-based study. J Clin Oncol. 2016;34:3175-82. 